\title{
Upper limb pain due to cervical hydatid cyst
}

\author{
Reza Rezaei ${ }^{1}$, Navid Soroush ${ }^{1}$, Kazem Rezaee $^{2}$, Vahid Zehi ${ }^{3}$ \\ ${ }^{1}$ Endoscopic and Minimally Invasive Surgery Research Center, Mashhad University of Medical Sciences, \\ Mashhad, Iran \\ ${ }^{2}$ Firoozabadi Hospital, Iran University of Medical Sciences, Tehran, Iran \\ ${ }^{3}$ Torbat-e-Heydariyeh University of Medical Sciences, Torbat-e-Heydariyeh, Iran
}

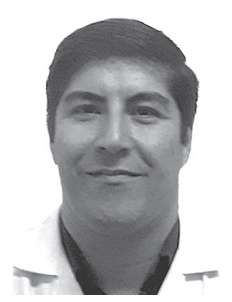

Kardiochirurgia i Torakochirurgia Polska 2021; 18 (2): 121-123

Hydatidosis, caused by the larval stage of Echinococcus granulosus, is the most frequently encountered type of hydatid disease in humans. Due to the close association that exists between sheep and dogs and humans, it is endemic to many parts of the world, particularly the Mediterranean countries including Turkey, the Middle East, South America, Africa, New Zealand, the Russian Federation, Central Asia, and Australia [1]. The adult tapeworm, a true hermaphrodite, lives in the intestine of the definitive hosts. Its terminal segment, which contains 500 to 800 eggs, is released into the intestinal tract of a dog and is expelled in dog faeces. The intermediate host, sheep or human, swallows the ovum, and the outer shell of the ovum dissolves in the duodenum, liberating an embryo. If the uncooked viscera of sheep are eaten by dogs, protoscolices develop into adult tapeworms, and the life cycle of the parasite is completed. In the intermediate host, the embryos enter the portal circulation in the intestines, and most of them are caught in the liver, whereas some reach the pulmonary arteries. Those entrapped within the lung parenchyma develop cysts in the lungs, whereas some may even pass through the lungs and reach the systemic circulation. The most frequently involved organ is the liver (65\%) because most of the embryos are trapped within it. Other involved sites are the lungs (25\%), and less frequently the spleen, kidneys, heart, bone, and central nervous system. The occurrence of hydatid cysts in the head and neck is rare even in countries where echinococcus infestation is endemic. Hydatid cysts involving the parotid region, parapharyngeal space, infratemporal fossa, maxillary sinus, and pterygopalatine fossa [2, 3] as well as the anterior or posterolateral cervical region 1 have been reported in the literature.

The patient was a 20-year-old man who complained of left upper limb pain. Despite numerous referrals to orthopaedists and neurologists and taking different medications such as analgesic and neuroleptic drugs, there was no improvement. During the course of treatment, the patient noticed a bulging of the left half of the neck, which gradually increased over a period of 2 to 3 months, extending to the mandibular and mastoid angles. So, a neck computed tomography (CT) scan was performed, and a huge cystic mass was found in the left posterior triangle of the neck that extended to left lung apex and paravertebral region and compressed the left brachial plexus (Figure 1). The decision was made to have surgery. According to the patient's occupation as a farmer and his contact with dogs and livestock, and the appearance of the cystic mass on the CT scan, a HAT test was performed, which was negative. After general anaesthesia, in a supine position, inserting a roll under the patient's shoulders, and hyperextension and rotation of the neck to the right, an incision in the anterior border of sternocleidomastoid (SCM) muscle was undertaken. There was a mass with cystic consistency that was in proximity and adhesion to the carotid sheath, oesophagus, vertebra, and brachial plexus. The mass was dissected from surrounding tissues carefully and removed completely from the surgical field. Then the mass was investigated, revealing a germinative layer of hydatid cyst within it. So the final diagnosis was cervical hydatid cyst. The patient was extubated postoperatively and albendazole was started. On the day after surgery, the patient had weakness in his left arm abduction due to neurapraxia. In the serial follow-up visits, this condition was resolved completely.

Echinococcosis is a zoonotic human infection caused by the larval hydatid worm of Echinococcus granulosus. A human can become accidentally involved in the life cycle of the parasite by ingesting the eggs shed in the faeces of an infected definitive host. Echinococcosis is endemic in many countries where sheep, dogs, and humans live in close contact. Parasite eggs that penetrate the organism hatch in the small intestine of the main host, pass into the portal venous system or lymphatic system, reach the liver and lungs, and finally form hydatid cyst lesions. Moreover, they can cross the hepatic sinusoid or pulmonary capillary barriers, and embryos get into systemic circulation and can settle in all the organs and structures in the body [4]. Hydatid cysts develop most frequently in the liver (65\%), lungs (25\%), and rarely in the spleen, kidneys, heart, bone, central nervous

Address for correspondence: Navid Soroush, Endoscopic and Minimally Invasive Surgery Research Center, Mashhad University of Medical Sciences, Mashhad, Iran, phone: 05138012840, fax: 05138402972, e-mail: emis@mums.ac.ir

Received: 17.12.2021, accepted: 30.01.2021. 

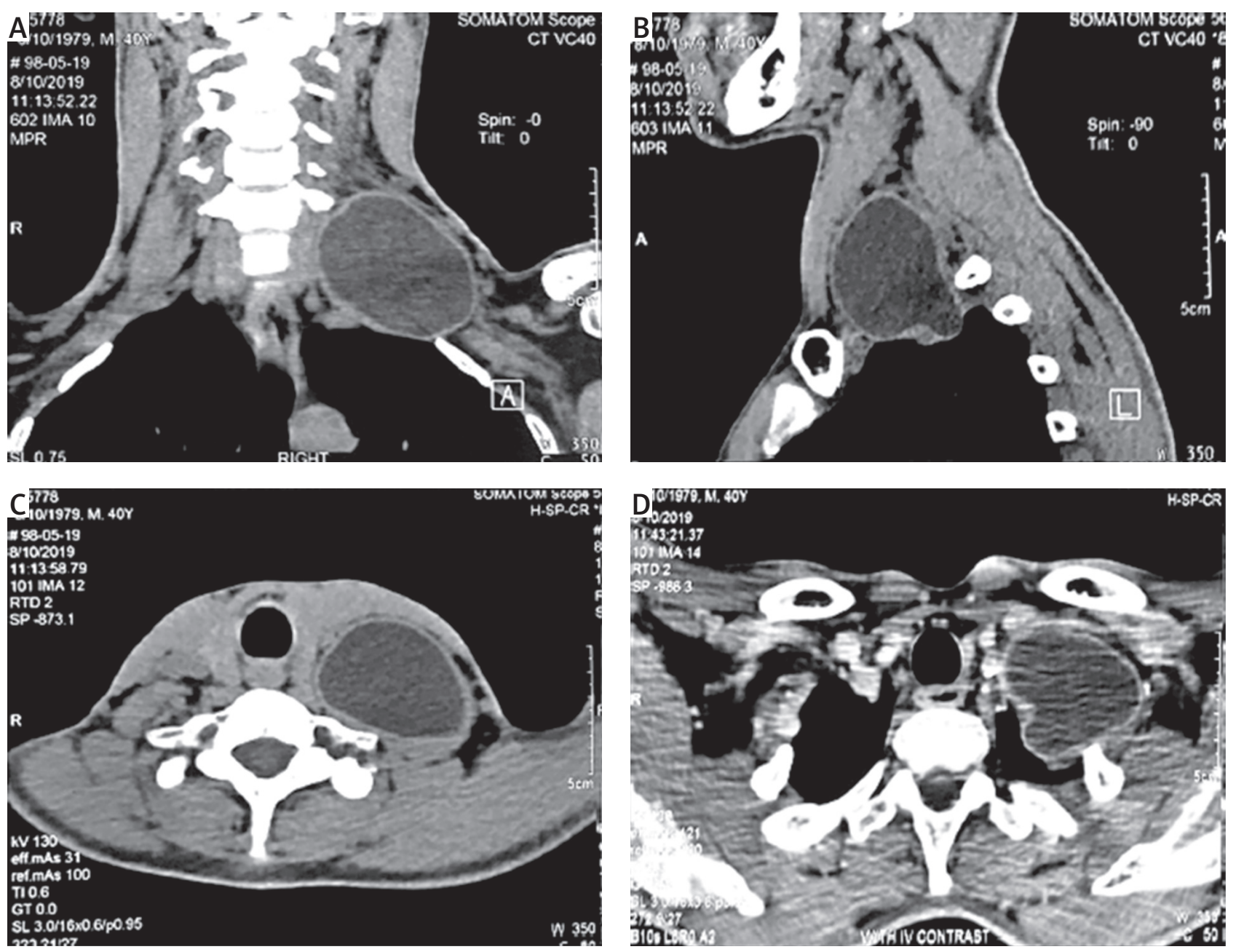

Figure 1. Sagittal, coronal, and axial views of cyst in CT scan

system, or other internal organs. The occurrence of hydatid cysts in the cervicofacial and maxillofacial regions is rare, with only a few case reports found in the literature. These localizations represent approximately $0.2 \%$ of $\mathrm{HD}$ cases. A proposed explanation for this observation is effective filtering effects of hepatic and pulmonary circulation, which trap the echinococcal larvae. In 10-15\% of cases, however, larvae can escape from this filtering effect and form hydatid cysts in other organs [5]. Sener et al. [6] provided an alternative mechanism for bypassing the hepatic and pulmonary circulation in the formation of primary widespread spinal and paraspinal hydatid cysts. Based on presence of portosystemic anastomoses in various anatomical locations, they proposed that the larvae penetrate the intestinal muscle and may directly enter the inferior vena cava system through small venous connections at the intestinal walls instead of entering the portal circulation. Systemic dissemination through the lymphatic route is another strong possibility in the case of unusual presentation sites [7].

Clinical signs and symptoms depend on the anatomic localization, size, and pressure of the enlarged cyst. Therefore, signs and symptoms are variable and never pathognomonic of hydatid cyst. A palpable slow-growing mass is the most constant clinical finding in soft-tissue hydatid disease. Symptoms due to their compressive effects on adjacent organs are another common finding [5]. Our patient presented initially with left upper limb pain because of the compressing effect on the brachial plexus. Gradually a bulging became apparent in the left side of the neck in 2-3 months.

Katilmis et al. [8] and Beji et al. [9] reported a case of a 33-year-old female patient presenting with a hydatid cyst in the lateral cervical region. Aijaz Ahmed Memon reported a rare case of hydatid cyst (Echinococcus granulosus) in the submandibular gland of a young man [10]. Mahmood Nouriyan et al. reported a hydatid cyst in the paraspinal muscle presenting with a cervical mass and pain [11]. Sultana et al. reported a case of primary cervical hydatid cyst in a 20-year-old female [7].

Iynen et al. reported a primary hydatid cyst in the left supraclavicular region of the neck [12]. Ahmad et al. reported a 46-year-old man with a hydatid cyst in the posterior cervical region [13].

Past medical history, family history, patient's occupation, and patient's residence may suggest a diagnosis of a hydatid cyst in differential diagnosis; unless suspected or demonstrative radiological findings are available, preop- 
erative diagnosis may be missed. Although immunological tests are valuable in the diagnosis of hydatid cysts, only a positive test is helpful. Therefore, complete reliance on serology for definitive diagnosis is not recommended. The hydatid cyst capsule may play a role in false-negative results in serological tests because of isolation of the parasite from the host immune system by the cyst capsule. Another proposed explanation is inadequate Th2 cell activation and cytokine production, which is implicated in immunoglobulin expression in cystic echinococcosis. Our patient's immunological test was also negative.

Imaging remains more sensitive than serodiagnosis, and a characteristic USG or CT examination visualizing cystic masses by demonstrating internal septae and daughter cysts in the presence of negative serologic results should still suggest the diagnosis of echinococcosis.

The diagnostic use of FNAB in hydatid disease is controversial. Some argue that no sequelae were observed attributable to aspiration for the diagnosis of hydatid cyst. However, it has not been advised because of the potential to precipitate acute anaphylaxis or to spread daughter cysts [14].

Therefore, clinicians should be aware of a possible diagnosis of a hydatid cyst that may be located in the cervical area, and they should preferably avoid any biopsy before surgery. When FNAB is performed, smears made from aspirated hydatid cyst fluid may show scolices, hooklets, or remnants of laminated membrane. Surgical removal is the most effective treatment of hydatid cyst. Surgeons must be careful to avoid spillage of cyst contents to avoid fatal anaphylaxis, recurrence, and multiple hydatidosis [15].

Hydatid disease is a widespread public health problem in developing countries. The possibility of hydatid disease, especially in endemic regions, should always be considered in the differential diagnosis of mesenchymal neoplasms or soft tissue masses in the neck or in the other parts of the body. The prognosis is excellent in hydatid cyst cases treated with total removal of the cyst without rupture.

\section{Disclosure}

The authors report no conflict of interest.

\section{References}

1. Abbassioun K, Amirjamshidi A. Diagnosis and management of hydatid cyst of the central nervous system. Part 1 . General considerations and hydatid disease of the brain. Neurosurg Quart 2001; 11: 1-9.

2. Bilgen C, Oner K, Ovql I, Kirazl VT. Vertebral hydatid disease presenting as a parapharyngeal and neck mass: a case report. Otolaryngol Head Neck Surg 2002; 126: 89-90.

3. Akhan O, Ensari S, Ozmen M. Percutaneous treatment of a parotid gland hydatid cyst: a possible alternative to surgery. Eur Radiol 2002; 12: 597-599.

4. Celik A, Turanli M, Kutun S, Delibasi T, Mengi N, Comert E, Aslan S, Altundag K, Cetin A. Unusual location of hydatid cyst: soft tissue mass in the neck. Eur Arch Otorhinolaryngol 2006; 263: 1147-1150.

5. Vasilevska V, Zafirovski G, Kirjas N, Janevska V, Samardziski M, KostadinovaKunovska S, Lozance K, Antevski B, Serafimoski V. Imaging diagnosis of musculoskeletal hydatid disease. Prilozi 2007; 28: 199-209.

6. Sener RN, Calli C, Kitis O, Yalman O. Multiple, primary spinalparaspinal hydatid cysts. Eur Radiol 2001; 11: 2314-2316.

7. Sultana N, Hashim TK, Jan SY, Khan Z, Malik T, Shah W. Primary cervical hydatid cyst: a rare occurrence. Diagnostic Pathol 2012; 7: 157.

8. Katilmis H, Ozturkcan S, Ozdemir I, Guvenc IA. Ozturan S. Primary hydatid cyst of the neck. Am J Otolaryngol 2007; 28: 205-207.

9. Beji M, Ben Messaoud M, Louzir B, Bouzaidi K, Ben Rhouma NM, Cherif J, Slim R, Kilani T, Daghfous J. Cervico-thoracic localization of a hydatid cyst. J Radiol 2004; 85: 135-137.

10. Memon AA, Shah SP, Ghumro AA. Hydatid cyst in a submandibular gland. J Surg Pak 2002; 7: 44-45.

11. Mahmood Nouriyan S, Mokhtari M, Abbasi Fard S, Nouriyan N. Primary solitary hydatid cyst in paraspinal cervical muscles: a case report and review of the literature. Neurol Neurochir Pol 2011; 45: 387-390.

12. Iynen I, Sogut O, Guldur ME, Kose R, Kaya H, Bozkus F. Primary hydatid cyst: an unusual cause of a mass in the supraclavicular region of the neck. J Clin Med Res 2011; 3: 52-54.

13. Ahmad S, Jalil S, Saleem Y, Suleman BA, Chughtai N. Hydatid cysts at unusual sites: reports of two cases in the neck and breast. J Pakistan Med Assoc 2010; 60: 232-234.

14. Sennaroglu L, Nerci M, Turan E, Sungur A. Infratemporal hydatid cyst: unusual location of echinococcosis. J Laryngol Otol 1994; 108: 601-603.

15. Izci Y, Tüzün Y, Seçer HI, Gönül E. Cerebral hydatid cyst: technique and pitfalls of surgical management. Neurosurg Focus 2008; 24: E15. 